\title{
PERSONALIZED DOSING OF CYCLOPHOSPHAMIDE IN THE TOTAL BODY IRRADIATION - CYCLOPHOSPHAMIDE CONDITIONING REGIMEN: A PHASE II TRIAL IN PATIENTS WITH HEMATOLOGIC MALIGNANCY
}

\author{
Jeannine S. McCune ${ }^{1,2}$, Ami Batchelder ${ }^{1}$, Katherine A. Guthrie ${ }^{1}$, Robert Witherspoon ${ }^{1,3}$, \\ Frederick R. Appelbaum ${ }^{1,3}$, Brian Phillips ${ }^{1}$, Paolo Vicini ${ }^{3,4}{ }^{\text {, David H. Salinger }}{ }^{3,4}$, and George \\ B. McDonald 1,3 \\ ${ }^{1}$ Clinical Research Division of the Fred Hutchinson Cancer Research Center, Seattle, Washington \\ 2University of Washington Schools of Pharmacy, Seattle, Washington \\ ${ }^{3}$ Medicine, Seattle, Washington
}

\begin{abstract}
This study investigates the efficacy and safety of personalized cyclophosphamide (CY) dosing in 50 patients receiving CY with total body irradiation (TBI). Participants received CY $45 \mathrm{mg} / \mathrm{kg}$ with subsequent therapeutic drug monitoring with Bayesian parameter estimation to personalize the second CY dose to a target area under the curve for carboxyethylphosphoramide mustard (a reporter for CY-derived toxins) and for hydroxycyclophosphamide (to ensure engraftment). The mean second CY dose was $66 \mathrm{mg} / \mathrm{kg}$; the total dose ranged from $45-145 \mathrm{mg} / \mathrm{kg}$. After completion of this phase II study, we compared participants' clinical outcomes to those of concurrent controls $(\mathrm{N}=100)$ who received TBI with standard CY doses of $120 \mathrm{mg} / \mathrm{kg}$. Patients receiving personalized CY dosing had significantly lower post-conditioning peak total serum bilirubin ( $\mathrm{p}=0.03)$; a $38 \%$ reduction in the hazard of acute kidney injury ( $\mathrm{p}=0.03$ ); and similar non-relapse and overall survival ( $\mathrm{p}=0.70$ and 0.63 , respectively) despite lower doses of $\mathrm{CY}$ in most patients.
\end{abstract}

\section{Keywords}

Hematologic malignancy; cyclophosphamide; hydroxycyclophosphamide; carboxyethylphosphoramide mustard; pharmacokinetics; population pharmacokinetics; therapeutic drug monitoring; hematopoietic cell transplantation; liver toxicity; renal toxicity; mortality; outcomes

\section{INTRODUCTION}

For 40 years, cyclophosphamide has been an integral component of conditioning regimens for patients undergoing allogeneic hematopoietic cell transplant (HCT). ${ }^{1-3}$ One common

\footnotetext{
Correspondence to: Jeannine S. McCune, Pharm.D., School of Pharmacy, Department of Pharmacy, University of Washington, Box 357630, Seattle, WA 98195, Telephone: 206-543-1412, Fax: 206-543-3835, Email: E-mail: jmccune@u.washington.edu.

${ }_{5}^{4}$ Current address: Pfizer Global Research \& Development, San Diego, CA.

${ }^{5}$ Current address: Amgen Inc., Seattle, WA.

Conflict of Interest

None of the authors declared a conflict of interest.
} 
conditioning regimen combines total body irradiation (TBI) with cyclophosphamide (CY) 120 $\mathrm{mg} / \mathrm{kg}$ administered in divided doses on each of two consecutive days. The purpose of the TBI/ CY conditioning regimen is two-fold: to minimize the risk of rejection of donor cells through its myeloablative effects, and, in patients with hematologic malignancy, to have an anti-tumor effect. ${ }^{3} \mathrm{TBI} / \mathrm{CY}$ conditioning, however, causes considerable regimen-related toxicity, particularly to hepatic sinusoids: destruction of sinusoidal endothelial cells, activation of stellate cells, deposition of extracellular matrix in sinusoids, and zone 3 hepatocyte necrosis (collectively known as sinusoidal obstruction syndrome or SOS) ${ }^{4}$ The clinical consequences of this liver injury include jaundice, hepatomegaly, portal hypertension, ascites, renal sodium retention, and acute kidney injury (AKI) ${ }^{4-8}$

Recent studies have elucidated the pathogenesis of SOS. Although generally not thought to be a liver toxin, there is now considerable evidence that $\mathrm{CY}$ is the primary cause of liver injury when used as part of myeloablative regimens for HCT. 9,10 When CY is placed in co-culture with hepatocytes and sinusoidal endothelial cells, toxic metabolites generated within hepatocytes damage endothelial cells. ${ }^{11}$ A prospective study of 148 patients undergoing TBI/ CY conditioning found that considerable interpatient variability in CY metabolism, and that the frequency of SOS, non-relapse mortality, and overall survival were related to how CY was metabolized. ${ }^{10}$ Carboxyethylphosphoramide mustard (CEPM), a metabolite of CY, was found to be a reporter molecule for hepatotoxins derived from $\mathrm{CY}$; patients having the greatest exposure to CEPM (as measured by the area under the curve, or $\mathrm{AUC}_{\mathrm{CEPM}}$ ) had the greatest frequency of severe liver injury and the worst outcomes. ${ }^{10}$ In our subsequent work, we developed a novel method for personalizing CY doses to greatly decrease the interpatient variability in $\mathrm{AUC}_{\mathrm{CEPM}}$, with the long-range goal of lowering the liver toxicity of the TBI/CY regimen. ${ }^{12}$ In a phase I study of 20 patients undergoing TBI/CY conditioning, CY doses were personalized using therapeutic drug monitoring after the first $\mathrm{CY}$ infusion. This was done by measuring $\mathrm{AUC}_{\mathrm{CEPM}}$ from 0 to 16 hours, then adjusting the second $\mathrm{CY}$ dose to achieve a total exposure $\left(\mathrm{AUC}_{0-48 \mathrm{hr}}\right.$ ) to CEPM of $325 \pm 25 \mu \mathrm{M} \bullet \mathrm{h} .{ }^{12} \mathrm{We}$ then demonstrated that using a population pharmacokinetic model provided a more accurate prediction of the target level of the metabolite CEPM, which was needed to achieve this personalized second CY dose. ${ }^{13}$

We now report the results of a phase II study of the TBI/CY conditioning regimen in 50 patients undergoing allogeneic HCT, in which we used therapeutic drug monitoring with Bayesian parameter estimation after the first CY dose to adjust the second CY dose. The aims of this study were to determine the frequency of liver and kidney injury, non-relapse mortality, relapse of malignancy, and survival among patients who received TBI 12 Gy plus personalized CY dosing. Upon completion of this phase II study, we compared the clinical outcomes of patients receiving personalized CY dosing to those of concurrent control patients who received TBI 12 Gy plus standard CY dosing at $120 \mathrm{mg} / \mathrm{kg}$ with identical supportive care (see Methods, Patient Selection).

\section{RESULTS}

\section{Demographics of the study cohorts}

Table 1 shows patient characteristics by $\mathrm{CY}$ dosing method. Patients who received personalized $\mathrm{CY}$ dosing were, on average, older and less likely to have received $400 \mathrm{cGy}$ testicular irradiation than those who received standard CY dosing of $120 \mathrm{mg} / \mathrm{kg}$. Aside from transplant year, the groups were fairly well matched on the remaining factors.

\section{Personalized CY dosing method: Pharmacokinetics and dose adjustments}

Patients participating in the phase II trial of personalized CY dosing received a first CY dose of $45 \mathrm{mg} / \mathrm{kg}$. The mean second CY dose was $66 \mathrm{mg} / \mathrm{kg}$ (range, $0-100 \mathrm{mg} / \mathrm{kg}$ ), and the mean 
total CY dose was $111 \mathrm{mg} / \mathrm{kg}$ (range, $45-145 \mathrm{mg} / \mathrm{kg}$ ). There were 15 patients whose total CY dose exceeded $120 \mathrm{mg} / \mathrm{kg}$. The mean $\mathrm{AUC}_{\mathrm{CEPM}}$ for the time from 0 to 48 hours was $302 \mu \mathrm{M} \bullet \mathrm{h}$ (median, $301 \mu \mathrm{M} \bullet \mathrm{h}$; range, $136-442 \mu \mathrm{M} \bullet \mathrm{h}$ ); the target AUC for minimization of adverse effects was $325 \pm 25 \mu \mathrm{M} \bullet \mathrm{h}$. The average percent deviation of the observed $\mathrm{AUC}_{\mathrm{CEPM}}$ for the time from 0 to 48 hours from our target of $325 \mu \mathrm{M} \bullet \mathrm{h}$ was $-7 \%$, ranging from $-58 \%$ to $+36 \%$. The mean $\mathrm{AUC}_{\mathrm{HCY}}$ for the time from 0 to 48 hours was $183 \mu \mathrm{M} \bullet \mathrm{h}$ (median, $181 \mu \mathrm{M} \bullet \mathrm{h}$; range, 53$285 \mu \mathrm{M} \bullet \mathrm{h}$ ); our target had been greater than $50 \mu \mathrm{M} \bullet \mathrm{h}$. The mean $\mathrm{AUC}_{\mathrm{CY}}$ for the time from 0 to 48 hours was $3530 \mu \mathrm{M} \bullet \mathrm{h}$ (median, $3496 \mu \mathrm{M} \bullet \mathrm{h}$; range, 915-5782 $\mu \mathrm{M} \bullet \mathrm{h}$ ).

To confirm our previous observation that using a Bayesian pharmacokinetic method provided a more accurate and consistent method of dose adjustment, ${ }^{13}$ we compared the predicted AUC of each CY metabolite, based on either the regression equations or the Bayesian pharmacokinetic method, with the observed AUC. In comparison to the regression-based dosing method, the predicted $\mathrm{AUC}_{\mathrm{CEPM}}$ from the MAP Bayesian pharmacokinetic estimation was more closely correlated to the observed $\mathrm{AUC}_{\mathrm{CEPM}}$. The mean percent error for the observed $\mathrm{AUC}_{\mathrm{CEPM}}$ from 0 to 48 hours was $-13.9 \%$ (range, $-60.4 \%$ to $33 \%$ ) with the regression method and $11.8 \%$ (range, $-16 \%$ to $39.1 \%$ ) for the MAP pharmacokinetics method. The mean second CY dose that the regression-based method would have recommended was $62 \mathrm{mg} / \mathrm{kg}$ (range $9-184 \mathrm{mg} / \mathrm{kg}$ ), compared to $66 \mathrm{mg} / \mathrm{kg}$ (range $0-100 \mathrm{mg} / \mathrm{kg}$ ).

The systemic exposure of CY and its metabolites were not evaluated in the concurrent control patients.

\section{Frequency of liver and renal injury in cases and controls}

The maximum value for total serum bilirubin from the day of transplant to day 20 (a measure of the toxicity of the conditioning regimen ${ }^{4,8}$ ) was significantly lower among patients who received personalized CY dosing, compared to those who received $120 \mathrm{mg} / \mathrm{kg}$ (Table 2).

Acute kidney injury (AKI) developed in $77 \%$ of patients receiving standard CY dosing, compared to $62 \%$ of those receiving personalized $\mathrm{CY}$ dosing — a reduction of $38 \%$ in the hazard of AKI ( $\mathrm{p}=0.03$ ) (Table 2, Figure 1). Patients with AKI were more likely to have had high maximum total serum bilirubin values during days 0 to 20 than those without AKI (Table 3). This association was stronger in those who received standard CY than in those who received personalized CY dosing, although the difference between groups was not statistically significant.

\section{Non-relapse mortality, relapse, and overall survival in cases and controls}

Table 2 shows analyses of time-to-event outcomes for cases and controls, with regard to these outcomes. The corresponding cumulative incidence plots are shown in Figure 2. Despite an overall reduction in total CY dose for most patients, the use of personalized CY dosing was not associated with worse outcomes in terms of relapse or overall survival when compared with standard CY dosing. There was also no evidence of lower non-relapse mortality with personalized $\mathrm{CY}$ dosing.

\section{Subgroup analysis of outcomes by type of malignancy and by risk of relapse after transplant}

After analyzing outcome measures for the study cohort as a whole, we subsequently conducted subgroup analyses to determine if personalized CY dosing benefited a subgroup of the overall population. The purpose of this analysis was for hypothesis generation only. The distribution of patients with lymphoid and myeloid malignancies by risk of relapse and method of CY dosing is displayed in Table 1. Personalized CY dosing was not associated with worse outcomes (relapse, death) in either lymphoid or myeloid malignancies when these subgroups are considered separately (Table 2, Figure 3A and 3B, Figure 4A and 4B). There was, however, a 
$40 \%$ reduction in the hazard of death in patients with myeloid malignancies that were conditioned with TBI and personalized CY dosing that was not statistically significant $(95 \%$ CI, 0.27 - 1.34) (Table 2, Figure 3A and 3B). Similarly, personalized CY dosing was not associated with worse outcomes (compared to standard CY dosing) when patients were analyzed by their risk of recurrent malignancy (Table 2, Figure 3C and 3D, Figure 4C and 4D).

\section{DISCUSSION}

This phase II trial of a conditioning regimen that combines total body irradiation $12 \mathrm{~Gy}$ with personalized dosing of $\mathrm{CY}$ demonstrates that 1 ) it is feasible to accurately target AUC of CY metabolite levels in individual patients using a Bayesian pharmacokinetic method; 2) the CY dose range to achieve the same metabolic endpoint varies over 3-fold ( $45-145 \mathrm{mg} / \mathrm{kg}$ total dose) and; 3) there was less liver and kidney injury with personalized CY dosing, when compared to the frequency of injury among a cohort of concomitant, well-matched patients receiving TBI and standard CY dosing at $120 \mathrm{mg} / \mathrm{kg}$.

The results of the phase II trial reported here confirm previous observations about the extreme variability in CY metabolism. ${ }^{10,12}$ Among patients receiving personalized CY dosing, there was a 3 -fold CY dosing range that was needed to achieve the same target metabolic endpoint. Normalizing exposure to the toxic metabolites of CY resulted in statistically significantly lower peak bilirubin levels and a lower frequency of kidney injury than in a comparison cohort of patients who received TBI followed by standard CY dosing of $120 \mathrm{mg} / \mathrm{kg}$ over two days. Although this was not a randomized trial, the comparison cohort was remarkably similar to the cohort receiving personalized CY dosing. Both cohorts were transplanted in approximately the same time frame (see Methods, Patient Selection), when transplant practices and supportive care, including drugs used for prophylaxis against infection, graft-versus-host disease (GVHD), and cholestatic liver injury, were identical. The results of this study confirm the hypothesis that $\mathrm{CY}$ is a proximate cause of liver injury when given in conjunction with TBI 12 Gy. ${ }^{10,11}$

The expected result was that reducing exposure to the toxic metabolites of CY in patients whose metabolism was destined to create high levels of toxin exposure would prevent liver and kidney injury, which was indeed true. Competing concerns, however, were that patients who received doses of CY lower than the standard $120 \mathrm{mg} / \mathrm{kg}$ would have reduced anti-tumor efficacy and a greater rate of relapse of the underlying malignancy, and conversely, that those who received higher CY doses would have more toxicity. The data show that personalized CY dosing in this regimen had no impact on the frequency of either relapse of malignancy or overall survival, compared to the concurrent control cohort. This finding is in agreement with our prior study that indicated no relationship exists between relapse of hematologic malignancies and exposure to $\mathrm{CY}$ and its metabolites when receiving TBI/CY conditioning. ${ }^{10}$

This somewhat discordant result-less organ toxicity but nearly identical outcome measures -may have resulted from the fixed $12 \mathrm{~Gy}$ dose of TBI that both cases and controls received. Our previous analysis demonstrated that aberrant CY metabolism and the total dose of TBI were independent factors in the pathogenesis of sinusoidal liver injury and non-relapse mortality. ${ }^{10}$ That is, patients at highest risk for SOS and mortality were those whose metabolism of $\mathrm{CY}$ yielded a greater quantity of toxins and who received the highest doses of TBI. Limiting the dose of TBI to 12 Gy appears to have reduced the frequency of liver injury even among patients who received standard CY dosing (our control cohort), compared to our historical patients whose doses of TBI varied. ${ }^{10}$ It is noteworthy that transplant centers that have used TBI doses of 10-12 Gy following standard doses of CY have consistently reported a lower frequency of fatal SOS ${ }^{14}$ than our center, where doses of TBI up to 14.4 Gy have been used along with CY $120 \mathrm{mg} / \mathrm{kg} .{ }^{4}$ The lack of an effect on non-relapse mortality after personalized 
CY dosing, despite less liver and kidney injury, may also be related to the fact that acute GVHD and infection during periods of intense immune suppression are important causes of nonrelapse mortality. We had no expectation that personalized $\mathrm{CY}$ dosing would affect the frequency of severe acute GVHD or fatal infection.

The average total dose of CY in our cohort who received personalized CY dosing $(111 \mathrm{mg} / \mathrm{kg})$ was $\sim 9 \%$ less than the standard dose; $14 \%$ of patients received less than $80 \mathrm{mg} / \mathrm{kg}$ total CY dose. There appeared to be no obvious penalty for a lower total dose of CY, as the rates of relapse of malignancy and survival were not different in the cohort who received personalized CY dosing, even when examined in subgroups sorted by risk of relapse after transplant and by type of malignancy. Given the small number of patients in each disease category, however, a modest impact on relapse rates could have been missed. We note that 15 of 50 patients received total CY doses in excess of $120 \mathrm{mg} / \mathrm{kg}$ to achieve the target metabolic endpoint; there was no evidence for either greater organ toxicity or improved anti-tumor outcomes in such patients.

There are some practical implications of this study. While the standard dose of CY (120 mg/ $\mathrm{kg}$ ) was chosen on an empiric basis over 30 years ago, the extreme variability in CY metabolism means that most patients who receive this dose are being exposed to increased liver toxicity, particularly when CY is combined with a second modality like TBI that is also toxic to sinusoidal endothelial cells. ${ }^{15}$ If a fixed dose of CY is to be used along with TBI, our data suggest that it should be $110 \mathrm{mg} / \mathrm{kg}$. While we have demonstrated that it is feasible to personalize doses of $\mathrm{CY}$, the methods for doing so are complicated and resource-intense, as they require bedside processing of blood specimens, refrigerated transport, and just-in-time, highly-specialized pharmacokinetic analysis that allows calculation of the second CY dose. 12,13 If TBI doses greater than $12 \mathrm{~Gy}$ are to be used in a TBI/CY regimen, personalized CY dosing may be necessary to avoid fatal regimen-related toxicity. There also may be individuals at increased risk of liver damage from conditioning therapy because of prior liver injury for whom the use of personalized CY dosing might be justified. ${ }^{16}$ Finally, one could argue that if personalized CY dosing were available, there could be a dose-escalation of TBI to achieve better outcomes related to relapse of malignancy, without jeopardizing survival because of regimen-related toxicity.

\section{METHODS}

\section{Patient selection}

From 2005-2007, patients over 18 years of age who had a malignant hematological disease unlikely to respond to conventional treatment and a suitable donor from an HLA-identical family member or unrelated allogeneic donor were considered for participation in a protocol where CY dosing was determined by therapeutic drug monitoring. High-resolution typing was performed for unrelated donors; donors who were an allele match or a one allele mismatch for HLA A, B, C, DRB1 or DQB1 were selected for favorable prognosis patients. ${ }^{17}$ Written consent was obtained using forms approved by the Institutional Review Board of the Fred Hutchinson Cancer Research Center. This study was registered with Clinical Trials.gov as trial identifier \# NCT00317785. In order to select control patients whose treatment differed only in the method of $\mathrm{CY}$ dosing, we reviewed the medical records of consecutive patients over 18 years of age who were treated for hematologic malignancy with allogeneic HCT following conditioning with TBI 12 Gy and CY $120 \mathrm{mg} / \mathrm{kg}$ during the years 2003-2007, under the aegis of a protocol approved by our Institutional Review Board. There were 102 such patients, two of whom had not given permission for review of records for research purposes, leaving 100 evaluable patients as controls. 


\section{Technique of hematopoietic cell transplantation}

Starting six days before infusion of donor hematopoietic cells, hyperfractionated total body irradiation (total dose $12 \mathrm{~Gy}$ ) was delivered via a linear accelerator as $200 \mathrm{cGy}$ fractions twice daily over 3 days, followed by intravenous $\mathrm{CY}$ administration on each of two consecutive days. Male patients with a diagnosis of ALL, biphenotypic leukemia, NHL, and CML in blast crisis remission also received testicular irradiation of $400 \mathrm{cGy}$ during conditioning therapy. For patients whose CY dose was to be personalized by therapeutic drug monitoring, CY was infused through a central venous access catheter over one to two hours on the first day at a dose of 45 $\mathrm{mg} / \mathrm{kg}$ based on adjusted ideal body weight. ${ }^{12}$ On the following day, a second infusion of CY was given to a maximum of $100 \mathrm{mg} / \mathrm{kg}$ (maximal total CY dose $145 \mathrm{mg} / \mathrm{kg}$ ), with dosing as described below. For patients whose CY dose was fixed at $120 \mathrm{mg} / \mathrm{kg}$ (standard CY dosing), CY was infused at a dose of $60 \mathrm{mg} / \mathrm{kg}$ on each of two consecutive days. During CY infusion days, patients received MESNA (2-mercaptoethane sulfonate) for uroepithelial prophylaxis, at a milligram dose equal to that of CY. A day of rest followed, with donor hematopoietic cell infusion occurring on day 0 . For patients in both groups, a calcineurin inhibitor and methotrexate were given as prophylaxis against GVHD, ursodiol against cholestatic liver disease, and fluconazole, acyclovir and trimethoprim-sulfamethoxazole as infection prophylaxis. ${ }^{18,19}$

\section{Therapeutic drug monitoring and dose adjustment of cyclophosphamide}

For patients receiving personalized CY dosing, blood samples were drawn from a central venous access catheter at the end of the first $\mathrm{CY}$ infusion and at 2, 4, 8, 16, 20, and 24 hours after the start of infusion. At each of these times, blood was collected in two tubes, one containing EDTA for CEPM and CY quantitation, and the other containing phenylhydrazine $\mathrm{HCl}$ to stabilize 4-hydroxycyclophosphamide (HCY). ${ }^{12}$ All samples were stored at the bedside at $4^{\circ} \mathrm{C}$ prior to sample transport. Following collection of the 16-hour blood sample, all samples were taken to the Pharmacology Laboratory for quantitation of the plasma concentrations of CEPM and HCY using liquid chromatography and mass spectroscopy methods, as described previously. ${ }^{12}$ Each patient's CY dose was adjusted based on pharmacokinetics to achieve a target plasma AUC over 0-148 hours for CEPM and HCY. The target $\mathrm{AUC}_{\mathrm{CEPM}}$ was set at $325 \pm 25 \mu \mathrm{M} \bullet \mathrm{h}$, a value derived from clinical endpoints and their relationship to $\mathrm{CY}$ pharmacokinetics from our prospective study of 147 patients. ${ }^{10}$ Briefly, $325 \mu \mathrm{M} \bullet \mathrm{h}$ was the highest value in the lowest quartile of CEPM exposure; patients whose $\mathrm{AUC}_{\mathrm{CEPM}}$ was within this quartile had the lowest frequency of organ toxicity, the lowest non-relapse mortality, and the best survival. ${ }^{10}$ Because of concern that lower $\mathrm{CY}$ doses needed to achieve the target $\mathrm{AUC}_{\mathrm{CEPM}}$ would lead to insufficient $\mathrm{AUC}_{\mathrm{HCY}}$, a minimum $\mathrm{AUC}_{\mathrm{HCY}}$ was set at $50 \mu \mathrm{M} \bullet \mathrm{h}$, based on prior data showing that this level of $\mathrm{HCY}$ exposure was consistent with engraftment.

${ }^{10}$ Personalized CY dosing was accomplished using Maximum A posteriori Probability (MAP) Bayesian estimation of the pharmacokinetic parameters, incorporating a blend of individualized pharmacokinetic data and a population parameter prior. ${ }^{13}$ This method was previously shown to more accurately predict 48 -hour AUCs than a method combining noncompartmental pharmacokinetic analysis of individual patient concentration-time data for $\mathrm{CY}$ metabolites and a regression equation relating the $\mathrm{AUC}_{0-16 \mathrm{hr}}$ to $\mathrm{AUC}_{0-48} \mathrm{hr} \cdot{ }^{12,13}$ The MAP Bayesian method used individual patient $0-16$ hour HCY and CEPM concentration-time data, together with a pharmacokinetic model and mean parameter values and their variance (derived from the prior study of 147 patients), to obtain the most likely estimates of the pharmacokinetic parameter values for that individual. ${ }^{20}$ This integrated model simultaneously describes the pharmacokinetics of CY, HCY and CEPM and includes autoinduction of CY to $\mathrm{HCY}$, thus allowing for a prediction of exposure conditional on any potential dosing scenario. The population prior parameters were not changed during this study. 
The complexity of the CY pharmacokinetic model and the necessity of rapid calculations led us to develop a customized software tool to perform MAP estimation of pharmacokinetic parameters. ${ }^{13}$ We developed the dose adjustment software in the statistical program R ( R Development Core Team, Vienna, Austria), and named it BaRD, or "Bayesian $\underline{\mathrm{R}}$ Dose" adjustment. With BaRD, we could read individual patient pharmacokinetic data of $\mathrm{HCY}$ and CEPM directly from an Excel ${ }^{\circledR}$ spreadsheet (Microsoft Corp, Redmond WA), estimate the individual CY pharmacokinetic model parameters, and then report the predicted $\mathrm{AUC}_{0-48} \mathrm{hr}$ for both HCY and CEPM over a wide range of potential CY second doses. The summary spreadsheet (BaRD input) included the first CY dose, the patient's age, and the HCY and CEPM concentration-time from the five samples obtained over 0-16 hours after the first CY dose. The output consisted of potential second CY doses in $5 \mathrm{mg} / \mathrm{kg}$ increments, with the option to obtain the output in $1 \mathrm{mg} / \mathrm{kg}$ increments. At each potential second CY dose, the expected $\mathrm{AUC}_{0-48 \mathrm{hr}}$ for both $\mathrm{HCY}$ and CEPM along with the $95 \%$ confidence intervals of achieving the combined target AUCs was obtained. The recommended second CY dose was subject to review and approval by one of us (JSM) such that the personalized CY dosing was the result of the BaRD proposed dose and review by a human expert. The second CY dose was communicated to the treating physician approximately 6 hours after the 16 hour blood sample had been obtained. Blood samples were also obtained after the personalized CY dose, at the end of infusion and at 2, 4, 8, 16, 20, and 24 hours after the start of infusion.

\section{Statistical analyses}

The outcomes of interest were liver disease, acute kidney injury, non-relapse mortality, relapse, and overall survival. Maximum total serum bilirubin levels in the first 20 days (reflecting liver injury caused by the conditioning regimen) and from day 21 to 100 (reflecting liver injury from other causes) were used as measures of liver disease for this analysis. Acute kidney injury (AKI) was defined as a doubling of baseline serum creatinine at any time during the first 100 days post-transplant. ${ }^{7}$ Cumulative incidence curves were used to estimate the probabilities of time-to-event outcomes. The statistical significance of differences in event rates was evaluated with the proportional hazards regression model. Death was treated as a competing risk in the analysis of AKI and relapse. Relapse of the underlying malignancy was treated as a competing risk in the analysis of non-relapse mortality. The maximum total serum bilirubin values were log-transformed to approximate normality, and compared by group via linear regression models. The association of AKI and the incidence of a maximum bilirubin value in days 0 20 higher than the median value for all patients were estimated with the logistic regression model. Factors considered as potential confounders of the relationships between the method of CY dosing and the outcomes included age, race, donor-recipient sex match, transplant year, donor type, receipt of testicular irradiation as part of the conditioning regimen, and risk of relapse as defined by disease type and stage. ${ }^{21}$ Such factors were retained in the model if their presence influenced the coefficient of interest (use of personalized CY dosing) by $10 \%$ or more. Reported p-values are two-sided, and based on the Wald statistic. No adjustments are made for multiple comparisons. The target accrual for this phase II study was 50 participants, which provided $88 \%$ power to observe a $16 \%$ decrease in day 200 non-relapse mortality, based on our historical experience with conditioning with TBI and standard doses of CY $(120 \mathrm{mg} / \mathrm{kg}$ for 2 days).

After study accrual was complete, we sought to confirm our prior observation ${ }^{12}$ that MAP Bayesian estimation provided a more accurate method for determination of the second CY dose than the noncompartmental analysis method. Noncompartmental analysis was used to estimate each individual patient's $\mathrm{AUC}_{\mathrm{CEPM}}$ values for the time from 0 to 16 hours. The estimate of the expected $\mathrm{AUC}_{\mathrm{CEPM}}$ for time 0 to 48 hours was then calculated using a regression equation relating the $\mathrm{AUC}_{\mathrm{CEPM}}$ from 0 to 16 hours and the $\mathrm{AUC}_{\mathrm{CEPM}}$ from 0 to 48 hours ${ }^{12}$ : $\mathrm{AUC}_{\mathrm{CEPM}}$ from $0-48$ hours equals 8.47 (AUC $_{\mathrm{CEPM}}$ for $0-16$ hours) ${ }^{0.813}$. The dose 
recommendation based on this noncompartmental analysis was calculated. In this manuscript, this method is referred to as the "regression method." In addition, the predicted AUC ${ }_{\mathrm{CEPM}}$ was calculated using the regression equation with the actual administered second CY dose. An assessment of predictive performance was based on the predicted $\mathrm{AUC}_{\mathrm{CEPM}}$ from 0 to 48 hours from either the regression method or the MAP Bayesian pharmacokinetics method, using the $\mathrm{AUC}_{\mathrm{CEPM}}$ as the actual measurement value in the calculation of precision. Precision was calculated by use of absolute percent error as follows: [(Observed-Predicted/Observed $) * 100]$. 22

\section{ACKNOWLEDGEMENTS}

Our research was supported by grants from the National Institutes of Health, National Cancer Institute (CA 18029, CA 15704). We are grateful to the study participants and the many nurses at the Seattle Cancer Care Alliance and University of Washington Medical Center who supported this protocol.

\section{REFERENCES}

1. Santos GW, et al. Marrow transplantation in man following cyclophosphamide. Transplant Proc 1971;3:400-404. [PubMed: 4398496]

2. Thomas ED, et al. Aplastic anaemia treated by marrow transplantation. Lancet 1972;1:284-289. [PubMed: 4109931]

3. Thomas ED, et al. Cure of leukemia by marrow transplantation. Leukemia Research 1977;1:67-70.

4. McDonald GB, et al. Veno-occlusive disease of the liver and multiorgan failure after bone marrow transplantation: a cohort study of 355 patients. Ann Intern Med 1993;118:255-267. [PubMed: 8420443]

5. DeLeve LD, Shulman HM, McDonald GB. Toxic injury to hepatic sinusoids: sinusoidal obstruction syndrome (veno-occlusive disease). Semin Liver Dis 2002;22:27-42. [PubMed: 11928077]

6. Fink JC, Cooper MA, Burkhart KM, McDonald GB, Zager RA. Marked enzymuria after bone marrow transplantation: a correlate of veno-occlusive disease-induced "hepatorenal syndrome". J Am Soc Nephrol 1995;6:1655-1660. [PubMed: 8749694]

7. Hingorani SR, et al. Acute renal failure after myeloablative hematopoietic cell transplant: incidence and risk factors. Kidney Int 2005;67:272-277. [PubMed: 15610251]

8. Gooley TA, Rajvanshi P, Schoch HG, McDonald GB. Serum bilirubin levels and mortality after myeloablative allogeneic hematopoietic cell transplantation. Hepatology 2005;41:345-352. [PubMed: 15660388]

9. de Jonge ME, Huitema AD, Beijnen JH, Rodenhuis S. High exposures to bioactivated cyclophosphamide are related to the occurrence of veno-occlusive disease of the liver following highdose chemotherapy. Br J Cancer 2006;94:1226-1230. [PubMed: 16622453]

10. McDonald GB, et al. Cyclophosphamide metabolism, liver toxicity, and mortality following hematopoietic stem cell transplantation. Blood 2003 Mar 1;101:2043-2048. [PubMed: 12406916]

11. DeLeve LD. Cellular target of cyclophosphamide toxicity in the murine liver: role of glutathione and site of metabolic activation. Hepatology 1996;24:830-837. [PubMed: 8855185]

12. McDonald GB, et al. Metabolism-based cyclophosphamide dosing for hematopoietic cell transplant. Clin Pharmacol Ther 2005;78:298-308. [PubMed: 16153400]

13. Salinger DH, et al. Real-time dose adjustment of cyclophosphamide in a preparative regimen for hematopoietic cell transplant: a Bayesian pharmacokinetic approach. Clin Cancer Res 2006;12:48884898. [PubMed: 16914577]

14. Ringden $\mathrm{O}$, et al. A randomized trial comparing busulfan with total body irradiation as conditioning in allogeneic marrow transplant recipients with leukemia: a report from the Nordic Bone Marrow Transplantation Group. Blood 1994;83:2723-2730. [PubMed: 8167351]

15. Geraci JP, Mariano MS, Jackson KL. Radiation hepatology of the rat: microvascular fibrosis and enhancement of liver dysfunction by diet and drugs. Radiat Res 1992;129:322-332. [PubMed: 1542720] 
16. McDonald GB. Review article: management of hepatic disease following haematopoietic cell transplant. Alimentary pharmacology \& therapeutics 2006;24:441-452. [PubMed: 16886910]

17. Petersdorf EW, et al. Limits of HLA mismatching in unrelated hematopoietic cell transplantation. Blood 2004;104:2976-2980. [PubMed: 15251989]

18. Ruutu T, et al. Ursodeoxycholic acid for the prevention of hepatic complications in allogeneic stem cell transplantation. Blood 2002;100:1977-1983. [PubMed: 12200355]

19. Appelbaum, FR.; Forman, SJ.; Negrin, RS.; Blume, KG., editors. Thomas' Hematopoietic Cell Transplant. Vol. 4th edn.. Malden, MA: Blackwell Publishing; 2009.

20. Qiu R, et al. Diminishing the risk of nonrelapse mortality in hematopoietic stem cell transplantation: Prediction of exposure to the cyclophosphamide metabolite carboxyethylphosphoramide mustard. Clin Pharmacol Ther 2004;76:270-280. [PubMed: 15371987]

21. Kahl C, et al. Relapse risk in patients with malignant diseases given allogeneic hematopoietic cell transplantation after nonmyeloablative conditioning. Blood 2007;110:2744-2748. [PubMed: 17595333]

22. Sheiner LB, Beal SL. Some suggestions for measuring predictive performance. J Pharmacokinet Biopharm 1981;9:503-512. [PubMed: 7310648] 


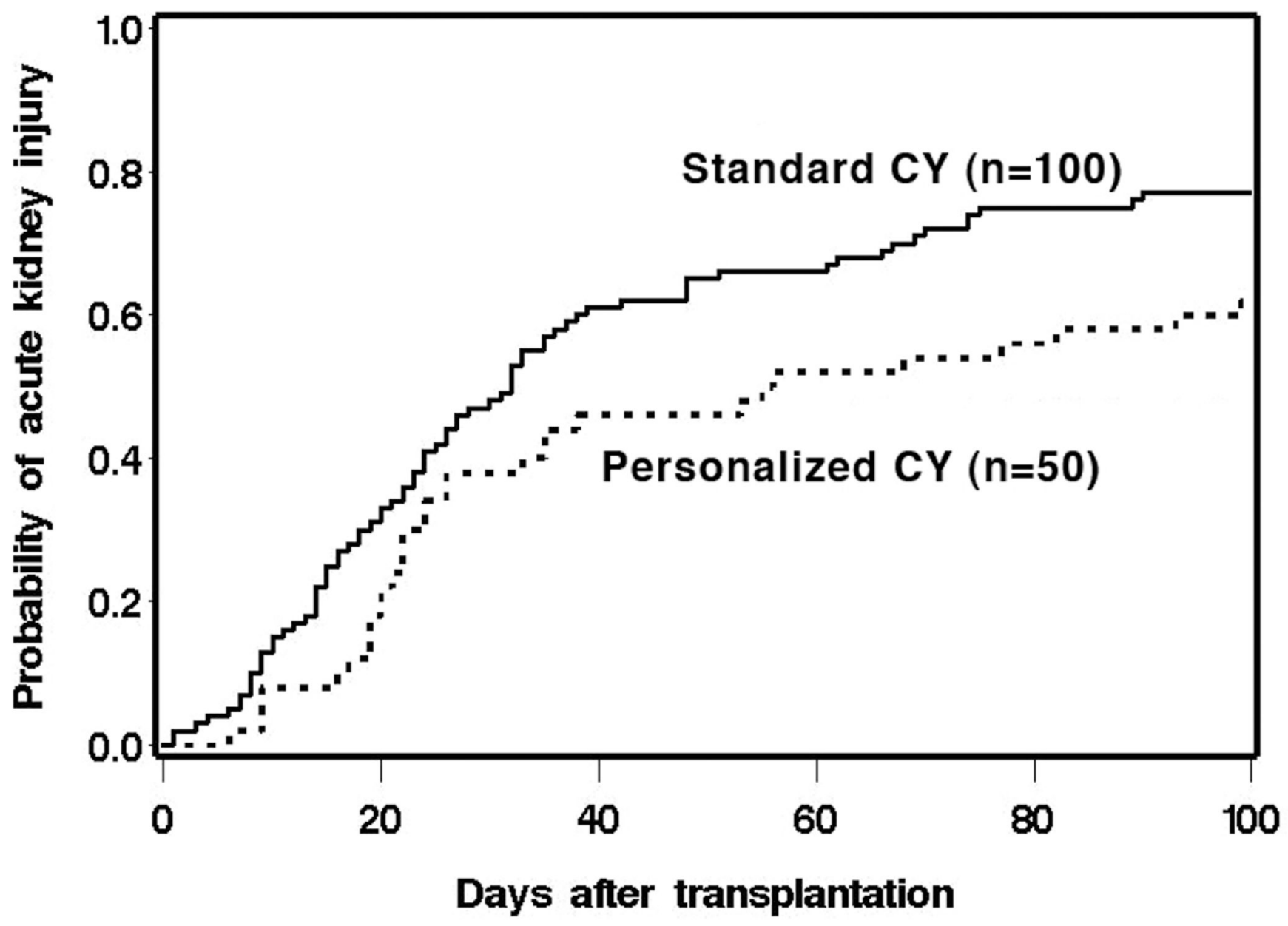

Figure 1.

Time to development of acute kidney injury by CY dosing method. 

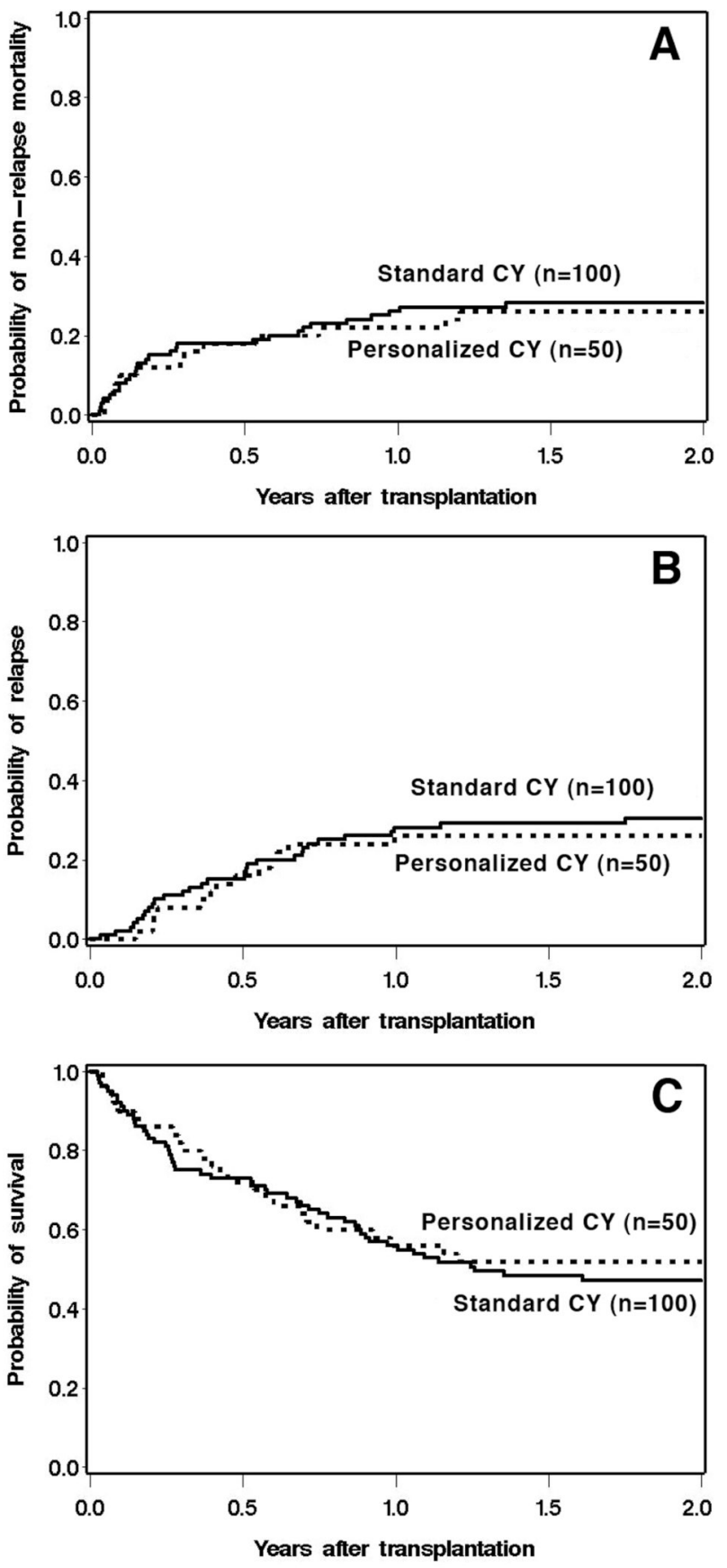

Figure 2.

Non-relapse mortality (A), relapse (B), and overall survival (C) by CY dosing method. 


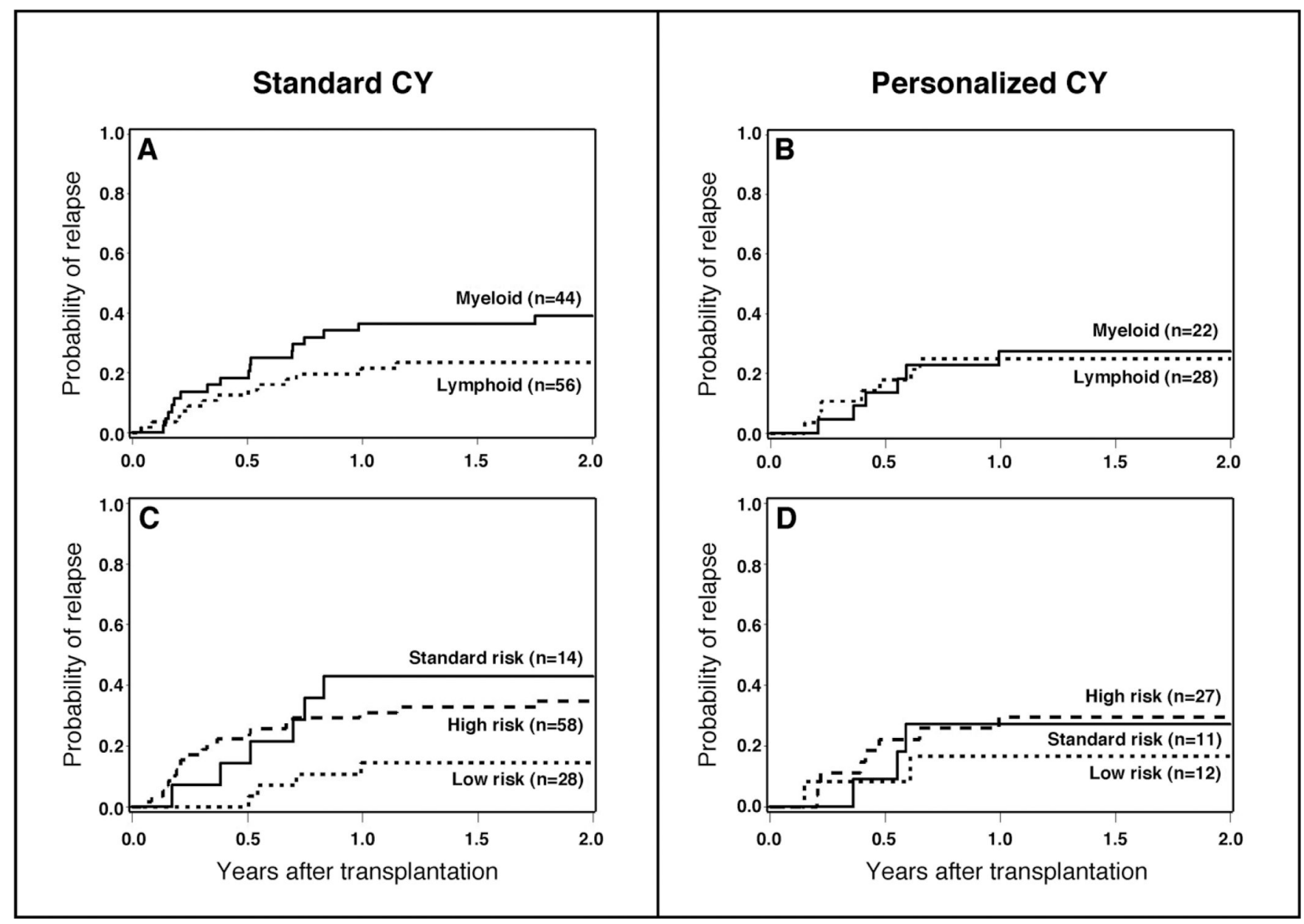

Figure 3.

Relapse of malignancy among patients receiving TBI 12 Gy plus standard CY dosing (120 mg/ $\mathrm{kg}$ ) vs. personalized CY dosing by type of hematologic malignancy (A and B) and by risk of relapse of malignancy after transplant $(\mathrm{C}$ and $\mathrm{D})$. 


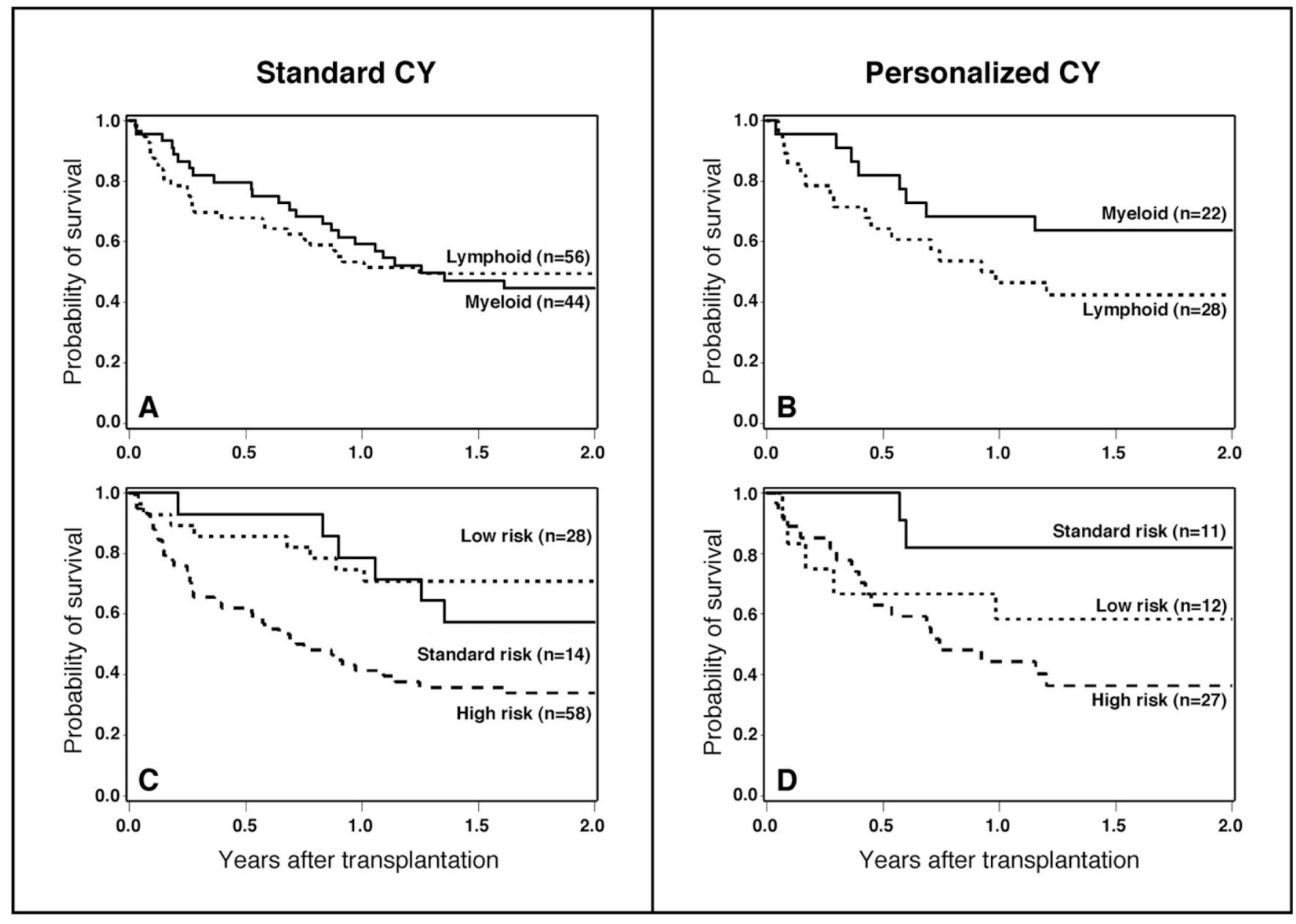

Figure 4.

Overall survival among patients receiving TBI 12 Gy plus standard CY dosing $(120 \mathrm{mg} / \mathrm{kg})$ vs. personalized CY dosing by type of hematologic malignancy (A and B) and by risk of relapse of malignancy after transplant (C and D). 
Table 1

Patient characteristics by CY dosing method.

\begin{tabular}{|c|c|c|}
\hline & $\begin{array}{c}\text { TBI } 12 \mathrm{~Gy}+ \\
\text { Standard CY dosing } \\
(120 \mathrm{mg} / \mathrm{kg}) \\
(\mathbf{N}=100) \\
\mathbf{N}(\%)\end{array}$ & $\begin{array}{c}\text { TBI } 12 \text { Gy }+ \\
\text { Personalized CY } \\
\text { dosing } \\
(\mathbf{N}=\mathbf{5 0}) \\
\mathbf{N}(\%)\end{array}$ \\
\hline \multicolumn{3}{|l|}{ Transplant year } \\
\hline $2003-2004$ & $55(55)$ & 0 \\
\hline 2005 & $30(30)$ & $15(30)$ \\
\hline $2006-2007$ & $15(15)$ & $35(70)$ \\
\hline \multicolumn{3}{|l|}{ Age (years) } \\
\hline $18-27$ & $26(26)$ & $11(22)$ \\
\hline $28-37$ & $25(25)$ & $14(28)$ \\
\hline $38-45$ & $31(31)$ & $6(12)$ \\
\hline$\geq 46$ & $18(18)$ & $19(38)$ \\
\hline Mean, $95 \%$ CI & $36,34-38$ & $39,36-43$ \\
\hline \multicolumn{3}{|l|}{ Race } \\
\hline White & $79(79)$ & $41(82)$ \\
\hline Non-white ${ }^{l}$ & $21(21)$ & $9(18)$ \\
\hline \multicolumn{3}{|l|}{ Donor } \\
\hline Matched sibling & $40(40)$ & $23(46)$ \\
\hline Mismatched relative & $5(5)$ & $2(4)$ \\
\hline Unrelated & $55(55)$ & $25(50)$ \\
\hline \multicolumn{3}{|l|}{ Sex: recipient - donor } \\
\hline Male - male & $35(35)$ & $10(20)$ \\
\hline Female - male & $17(17)$ & $8(16)$ \\
\hline Female - female & $18(18)$ & $12(24)$ \\
\hline Male - female & $30(30)$ & $20(40)$ \\
\hline \multicolumn{3}{|l|}{ Risk of relapse } \\
\hline Low & $28(28)$ & $12(24)$ \\
\hline \multicolumn{3}{|l|}{ Lymphoid malignancies: } \\
\hline $\begin{array}{l}\text { Acute lymphoblastic leukemia (ALL), } \\
\text { first complete remission (CR) }\end{array}$ & 22 & 10 \\
\hline $\begin{array}{l}\text { Non-Hodgkin's lymphoma (NHL), } \\
\text { Burkitt's Disease or diffuse large } \\
\text { cell, remission }\end{array}$ & 2 & 2 \\
\hline NHL, Follicular, relapse & 3 & 0 \\
\hline NHL, Mantle Cell, refractory relapse & 1 & 0 \\
\hline Myeloid malignancies & 0 & 0 \\
\hline Standard & $14(14)$ & $11(22)$ \\
\hline \multicolumn{3}{|l|}{ Lymphoid malignancies: } \\
\hline Chronic lymphocytic leukemia & 0 & 1 \\
\hline \multicolumn{3}{|l|}{ Myeloid malignancies: } \\
\hline $\begin{array}{l}\text { Acute myeloid leukemia (AML), } 1^{\text {st }} \text { or } \\
2^{\text {nd }} \text { CR }\end{array}$ & 10 & 10 \\
\hline Acute promyelocytic leukemia, $2^{\text {nd }} \mathrm{CR}$ & 1 & 0 \\
\hline
\end{tabular}




\begin{tabular}{|c|c|c|}
\hline & $\begin{array}{c}\text { TBI } 12 \mathrm{~Gy}+ \\
\text { Standard CY dosing } \\
(\mathbf{1 2 0} \mathrm{mg} / \mathrm{kg}) \\
(\mathbf{N}=100) \\
\mathbf{N}(\%)\end{array}$ & $\begin{array}{c}\text { TBI 12 Gy }+ \\
\text { Personalized CY } \\
\text { dosing } \\
(\mathbf{N}=\mathbf{5 0}) \\
\mathbf{N}(\%)\end{array}$ \\
\hline $\begin{array}{l}\text { Chronic myeloid leukemia (CML), } \\
\text { Chronic Phase }\end{array}$ & 3 & 0 \\
\hline High & $58(58)$ & $27(54)$ \\
\hline \multicolumn{3}{|l|}{ Lymphoid malignancies: } \\
\hline $\begin{array}{l}\mathrm{ALL}, \geq 1^{\text {st }} \text { relapse or primary refractory } \\
\text { or refractory relapse }\end{array}$ & 11 & 4 \\
\hline $\mathrm{ALL}, \geq 2^{\text {nd }} \mathrm{CR}$ & 11 & 8 \\
\hline $\begin{array}{l}\text { NHL in relapse (Burkitt's Disease, } \\
\text { diffuse large cell, T cell) }\end{array}$ & 5 & 2 \\
\hline NHL, T-cell, $2^{\text {nd }}$ CR & 0 & 1 \\
\hline Hodgkin's Disease, refractory relapse & 1 & 0 \\
\hline \multicolumn{3}{|l|}{ Myeloid malignancies: } \\
\hline $\mathrm{AML} \geq 1^{\text {st }}$ relapse or primary refractory & 14 & 7 \\
\hline Secondary AML & 3 & 1 \\
\hline Biphenotypic leukemia & 6 & 1 \\
\hline $\begin{array}{l}\text { CML, accelerated phase or blast } \\
\text { crisis/remission }\end{array}$ & 7 & 3 \\
\hline Testicular irradiation $(400 \mathrm{cGy})^{2}$ & $24(24)$ & $7(14)$ \\
\hline
\end{tabular}

${ }^{1}$ Non-white includes the following categories: Asian, Black or African-American, Native Hawaiian/Pacific Islander, Multiple races, and Unknown.

2 Testicular irradiation was given during conditioning therapy to male patients with ALL ( $N=23$ ), NHL ( $N=4$ ), biphenotypic leukemia ( $N=3$ ), and $C M L$ in remission following blast crisis $(\mathrm{N}=1)$. 
Table 2

Patient outcomes by CY dosing method ${ }^{I}$

\begin{tabular}{|c|c|c|c|c|}
\hline & $\begin{array}{c}\text { TBI } 12 \text { Gy + } \\
\text { Standard CY } \\
\text { dosing } \\
(120 \text { mg/kg) } \\
(\mathbf{N}=100)\end{array}$ & $\begin{array}{c}\text { TBI } 12 \text { Gy + } \\
\text { Personalized } \\
\text { CY dosing } \\
(\mathbf{N}=50)\end{array}$ & HR (95\% CI) & p-value \\
\hline \multicolumn{5}{|c|}{ Total serum bilirubin values: } \\
\hline Days 0-20 & $\begin{array}{c}1.7 \mathrm{mg} / \mathrm{dL} \\
(0.4-18.3)\end{array}$ & $\begin{array}{l}1.3 \mathrm{mg} / \mathrm{dL} \\
(0.7-8.8)\end{array}$ & & 0.03 \\
\hline $\begin{array}{l}\text { Day of maximum } \\
\text { serum bilirubin } \\
\text { (day 0-20) }\end{array}$ & $\begin{array}{l}\text { Day } 11 \\
(0-20)\end{array}$ & $\begin{array}{l}\text { Day } 10 \\
(1-20)\end{array}$ & & \\
\hline Days 21-100 & $\begin{array}{l}1.4 \mathrm{mg} / \mathrm{dL}^{2} \\
(0.5-35.0)\end{array}$ & $\begin{array}{l}1.1 \mathrm{mg} / \mathrm{dL}^{3} \\
(0.5-34.3)\end{array}$ & & 0.47 \\
\hline $\begin{array}{l}\text { Day of maximum } \\
\text { serum bilirubin } \\
\text { (day 21-100) }\end{array}$ & $\begin{array}{c}\text { Day } 27 \\
(21-99)\end{array}$ & $\begin{array}{c}\text { Day } 47 \\
(21-99)\end{array}$ & & \\
\hline \multicolumn{5}{|c|}{ Acute Kidney Injury 4} \\
\hline No & $23(23)$ & $19(38)$ & & \\
\hline Yes & 77 (77) & $31(62)$ & $0.62(0.40-0.95)$ & 0.03 \\
\hline \multicolumn{5}{|l|}{ Overall survival } \\
\hline Alive & $44(44)$ & $26(52)$ & & \\
\hline Died & $56(56)$ & $24(48)$ & $0.89(0.55-1.44)$ & 0.63 \\
\hline \multicolumn{5}{|c|}{ Non-relapse mortality } \\
\hline No & $71(71)$ & $37(74)$ & & \\
\hline Yes & $29(29)$ & $13(26)$ & $0.88(0.46-1.70)$ & 0.70 \\
\hline \multicolumn{5}{|l|}{ Relapse } \\
\hline No & $66(66)$ & $37(74)$ & & \\
\hline Yes & $34(34)$ & $13(26)$ & $0.81(0.42-1.54)$ & 0.52 \\
\hline \multicolumn{5}{|c|}{ Low and standard risk disease } \\
\hline Total & 42 & 23 & & \\
\hline Alive & $25(60)$ & $16(70)$ & & \\
\hline Died & $17(40)$ & $7(30)$ & $0.95(0.38-2.35)$ & 0.91 \\
\hline \multicolumn{5}{|l|}{ High risk disease } \\
\hline Total & 58 & 27 & & \\
\hline Alive & $19(33)$ & $10(37)$ & & \\
\hline Died & $39(67)$ & $17(63)$ & $0.88(0.50-1.56)$ & 0.67 \\
\hline \multicolumn{5}{|l|}{ Lymphoid disease } \\
\hline Total & 56 & 28 & & \\
\hline Alive & $26(46)$ & $12(43)$ & & \\
\hline Died & $30(54)$ & $16(57)$ & $1.14(0.62-2.11)$ & 0.67 \\
\hline \multicolumn{5}{|l|}{ Myeloid disease } \\
\hline Total & 44 & 22 & & \\
\hline Alive & $18(41)$ & $14(64)$ & & \\
\hline Died & $26(59)$ & $8(36)$ & $0.60(0.27-1.34)$ & 0.21 \\
\hline
\end{tabular}


2 Evaluable in 96 patients

3 Evaluable in 48 patients

${ }^{4}$ Acute kidney injury is defined as a doubling of baseline serum creatinine. 
Table 3

Maximum total serum bilirubin values (mg/dL) during days $0-20$ by acute kidney injury (AKI).

\begin{tabular}{|c|c|c|c|}
\hline & No AKI & AKI & p-value \\
\hline \multicolumn{4}{|l|}{ All patients } \\
\hline Median (range) & $1.3(0.6-5.9)$ & $1.8(0.4-18.3)$ & \\
\hline \multicolumn{4}{|l|}{ Total serum bilirubin } \\
\hline$\leq 1.5 \mathrm{mg} / \mathrm{dL}: \mathrm{N}(\%)$ & $29(69)$ & $45(42)$ & 0.003 \\
\hline$>1.5 \mathrm{mg} / \mathrm{dL}$ & $13(31)$ & $68(58)$ & \\
\hline \multicolumn{4}{|l|}{ Standard CY dosing } \\
\hline \multicolumn{4}{|l|}{ Total serum bilirubin } \\
\hline$\leq 1.5 \mathrm{mg} / \mathrm{dL}$ & $16(70)$ & $28(36)$ & \\
\hline$>1.5 \mathrm{mg} / \mathrm{dL}$ & $7(30)$ & $49(64)$ & 0.007 \\
\hline \multicolumn{4}{|l|}{ Personalized CY dosing } \\
\hline \multicolumn{4}{|l|}{ Total serum bilirubin } \\
\hline$\leq 1.5 \mathrm{mg} / \mathrm{dL}$ & $13(68)$ & $17(55)$ & \\
\hline$>1.5 \mathrm{mg} / \mathrm{dL}$ & $6(32)$ & $14(45)$ & 0.34 \\
\hline
\end{tabular}

